\title{
蓬勃发展的中国生物医用材料
}

陈学思 ${ }^{1,2,3}$

1. 中国科学院长春应用化学研究所, 中国科学院生态环境高分子材料重点实验室, 长春 130022 ;

2. 吉林省生物医用高分子材料工程实验室, 长春 130022;

3. 环保高分子材料开发与应用国家地方联合工程研究中心(吉林), 长春 130022

E-mail: xschen@ciac.ac.cn

\section{Flourishing research in Chinese biomedical materials}

\author{
Xuesi Chen ${ }^{1,2,3}$ \\ ${ }^{1}$ Key Laboratory of Polymer Ecomaterials, Chinese Academy of Sciences, Changchun Institute of Applied Chemistry, Chinese Academy of Sciences, \\ Changchun 130022, China; \\ ${ }^{2}$ Jilin Biomedical Polymers Engineering Laboratory, Changchun 130022, China; \\ ${ }^{3}$ National and Local Joint Engineering Research Center for the Development and Application of Environmentally Friendly Polymer Materials, Chang- \\ chun 130022, China \\ E-mail: xschen@ciac.ac.cn
}

doi: 10.1360/TB-2021-0362

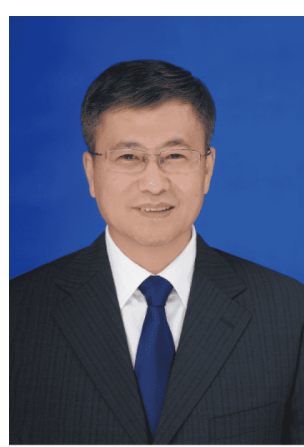

\section{陈学思}

中国科学院长春应用化学研究所 研究员, 中国科学院生态环境高分 子材料重点实验室学术委员会副 主任. 目前主要从事生物医用高分 子材料、组织工程和再生医学、 药物缓释载体材料、聚氨基酸水 凝胶、聚乳酸产业化等研究, 以及 聚乳酸和聚-已内酯产业化的研究 与开发.
生物医用材料是用来对生命体进行诊断、治疗、修复或替换其病损组织、 器官或增进其功能的材料. 早在古代时期, 一些天然的材料如棉麻纤维、马䦊等 即被用来作为缝合线缝合伤口, 古代中国和古埃及的墓葬中就被发现有假牙、 假鼻、假耳等。进入20世纪以来, 随着合成化学、特别是高分子材料科学的发 展, 生物医用材料的发展进入快车道. 近年来, 随着生命科学的发展和大健康时 代的到来, 生物医用材料的发展更呈现多点开花的蓬勃之势. 目前, 生物医用材 料已经成为材料学科中发展最快、也最具前景的方向之一, 生物医用材料产业 也已成为低能耗、高附加值新兴产业的代表.

随着对生命体认识的不断深入，生物医用材料的研究也在进一步向更广 阔、更深入的方向进军. 从基础原材料的合成、纳米组装体的制备、宏观尺寸 材料的构建, 到药物传输新技术、材料与细胞或机体的相互作用研究等, 材料化 学与生物医学的交叉不断深入, 并催生了很多新兴学科的出现. 中国学者在生物 医用材料的各领域都开展了积极的研究, 成为生物医用材料国际舞台上的一支 重要力量. 为集中体现中国学者在生物医用材料领域的最新研究进展, 促进行业 对生物医用材料研究现状的了解, 《科学通报》组织出版了“生物医用材料专 题”，邀请了相关领域的优秀学者撰稿，分别从新型生物医用材料的合成、生物 医用水凝胶材料、生物医用材料的功能应用以及材料与细胞的相互作用等方面 展开了论述, 系统介绍各自在生物医用材料的基础前沿领域的最新研究进展.

苏州大学殷黎晨课题组 ${ }^{[1]}$ 介绍了基于开环聚合的聚氨基酸材料的二级结构 效应及调控研究. 聚氨基酸是一类具有良好生物相容性和可降解性的合成高分 子材料. 与天然蛋白质一样, 聚氨基酸的主链氢键作用也赋予了其丰富的二级结 
构, 而该结构特性对聚氨基酸材料的组装行为, 以及在穿膜、基因递送、抗菌性能、蛋白修饰等生物医学应用方 面都有直接影响. 青岛科技大学孙静课题组 ${ }^{[2]}$ 介绍了新型聚类肽高分子材料及其在生物医用领域的应用. 聚类肽高 分子是一种新型的具有良好生物相容性的高分子材料, 由于其酰胺键的活泼氢被取代, 聚类肽主链结构中消除了

聚肽固有的多重氢键作用, 具有较为柔顺的主链结构, 从而产生新的功能特性和应用. 复旦大学俞麟课题组 ${ }^{\left[{ }^{3}\right.}$ 介绍 了两亲性共聚物热致水凝胶的研究. 随温度升高而发生溶胶-凝胶转变的热致水凝胶是一类重要的生物医用材料, 以可注射的方式用于药物持续释放的储库或细胞生长的支架. 目前, 基于聚乙二醇-聚氨基酸共聚物、聚有机膦 腈、聚乙二醇-聚酯共聚物的热致凝胶化体系都已被开发出来, 展现了良好的应用前景. 中国科学院长春应用化学 研究所贺超良课题组 ${ }^{[4]}$ 介绍了氨基酸残基手性对肽基水凝胶性能的影响. 用于构建肽基水凝胶的氨基酸残基的手 性对水凝胶的性能具有显著的影响. 例如, 在肽基水凝胶的骨架中引入 $\mathrm{D}$ 型氨基酸会增强其水解耐受性, 并增强材 料在宿主体内的免疫效应. 华南理工大学杨显珠课题组 ${ }^{[5]}$ 介绍了一类新型的聚磷酸酯/聚乙二醇复合水凝胶的构建 及性能. 该复合水凝胶能够显著增强碱性磷酸酶的活性, 提高钻沉积, 在细胞支架方面具有一定的应用潜力. 南开 大学丁丹课题组 ${ }^{[6]}$ 介绍了聚集态分子内运用触发的生物光热诊疗研究. 通过调控分子内的运动方式和分子聚集态 行为可以实现有效的光热转化, 在光声成像、热红外成像和光热治疗等应用方面显现出发展优势. 南开大学刘阳 课题组 ${ }^{[7]}$ 介绍了纳米材料用于调控癌症免疫应答方面的研究. 近年来, 癌症免疫疗法成为癌症治疗中最具潜力的一 类疗法, 然而, 当前的肿瘤免疫疗法依然面临着响应率低等问题. 了解癌症免疫疗法所面临问题的背后原因, 发展 基于纳米材料的新型技术用于调控癌症的免疫应答率, 对于提高免疫疗法的临床疗效非常有意义. 四川大学魏强 课题组 ${ }^{[8]}$ 介绍了对细胞是怎样感知和响应微环境机械力学性能的研究. 细胞力学刺激与响应在细胞的增殖分化、 胚胎发育、疾病进展等生物过程中扮演着重要角色. 了解细胞的力学响应机制, 将助力生物材料研究学者对细胞 和生物材料相互作用的理解, 推动新型生物材料的研究和开发.

本专题的出版得到了来自国内多家单位相关研究组的大力支持, 以及审稿人和编辑部工作人员的竭力相助. 在此, 对他们的辛勤付出表示哀心的感谢. 诚然, 上述研究仅是对中国生物医用材料蓬勃发展之一隅的展现, 我们 也希望后续能够对该领域更多的研究成果予以报道, 助力这一领域的产、学、研、用的融合, 推动生物医用材料 基础研究和应用产业的发展.

\section{参考文献}

1 Ge C L, Liu Y, Yin L C. Effect and regulation of the secondary structure of synthetic poly( $\alpha$-amino acid) based on ring-opening polymerization (in Chinese). Chin Sci Bull, 2021, 66: 2217-2230 [葛成龙, 刘勇, 殷黎晨. 基于开环聚合的聚氨基酸材料的二级结构效应及调控. 科学通报, 2021, 66: 2217-2230]

2 Lin M, Sun J. The recent progress of novel polypeptoid materials and biomedical applications (in Chinese). Chin Sci Bull, 2021, 66: $2231-2244$ [林 敏, 孙静. 新型聚类肽生物高分子材料及其在生物医用领域的应用. 科学通报, 2021, 66: 2231-2244]

3 Wang Y B, Yu L, Ding J D. Progress of amphiphilic copolymers thermogels (in Chinese). Chin Sci Bull, 2021, 66: 2245-2260 [王耀本, 俞麟, 丁建 东. 两亲性共聚物热致水凝胶. 科学通报, 2021, 66: 2245-2260]

4 Wang T R, Li G, He C L, et al. Effects of the chirality of amino acid residues on the properties of peptide-based hydrogels (in Chinese). Chin Sci Bull, 2021, 66: 2261-2275 [王天然, 李杲, 贺超良, 等. 氨基酸残基手性对肽基水凝胶性能的影响. 科学通报, 2021, 66: 2261-2275]

5 Zhang Z H, Yang X Z. Synthesis and characterization of polyphosphoester/polyethylene glycol composite hydrogels (in Chinese). Chin Sci Bull, 2021, 66: 2312-2318 [张正海, 杨显珠. 聚磷酸酯/聚乙二醇复合水凝胶的构建及性能. 科学通报, 2021, 66: 2312-2318]

6 Chen M, Ding D. Biophotothermal applications boosted by intramolecular motions from aggregates (in Chinese). Chin Sci Bull, 2021, 66: 22762287 [陈明, 丁丹. 聚集态分子内运动触发的生物光热诊疗. 科学通报, 2021, 66: 2276-2287]

7 Zhang Z Z, Zheng Y D, Liu Y. Recent progress of nanomaterials for regulating cancer immune responses (in Chinese). Chin Sci Bull, 2021, 66: 2288-2302 [张展展, 郑雅丹, 刘阳. 纳米材料用于调控癌症免疫应答. 科学通报, 2021, 66: 2288-2302]

8 Sun Q, Wei Q, Zhao C S. How do the cells sense and respond to the microenvironment mechanics (in Chinese)? Chin Sci Bull, 2021, 66: 23032311 [孙骞, 魏强, 赵长生. 细胞怎样感知与响应微环境机械力学性能. 科学通报, 2021, 66: 2303-2311] 